\title{
Air Terjun Jaga Satru Sebagai Salah Satu Destinasi Wisata Alternative di Wilayah Bali Timur
}

\author{
I Gusti Ketut Sukadana ${ }^{1}$, I Made Astika ${ }^{2}$, I Gusti Ngurah Dwijana ${ }^{3}$
}

\begin{abstract}
Astract
Potensi Desa Duda Timur Kecamatan Selat Kabupaten Karangasem yang terdiri dari sembilan dusun dengan tofografi wilayah berbukit, produk unggulan adalah salak Bali. Ada juga potensi pariwisata air terjun Jaga Satru, Bukit Putung, Pesiraman Dedari dll. Kurangnya promosi mengakibatkan tidak terkelola dengan baik. Progran KKN-PPM 2018 dilaksanakan kegiatan penataan air terjun Jaga Satru dan sumber air Suda Mala sebagai tempat wisata berupa penataan akses jalan, sehingga dapat menjadi tempat rekreasi pilihan di bali timur. Kegiatan sosialisasi dan promosi desa wisata dengan cara pembuatan vidio desa wisata dan ditayangkan di Bali TV, pembuatan petunjuk jalan menuju obyek wisata air terjun, pembuatan baliho air terjun dipasang di jalan masuk menuju desa Duda Timur. Target program KKN-PPM adalah: Berfungsinya air terjun Jaga Satru dan sumber air Suda Mala sebagai tempat rekreasi, tertatanya akses jalan menuju obyek wisata air terjun Jaga Satru dan sumber air Suda Mala. Terealisasikannya vidio desa wisata, terlaksana kegiatan promosi secara online. Metode pelaksanaan yaitu: Metode pendampingan pengerjaan fasilitas penunjang. Metode gotong royong dalam pelaksanaan kegiatan oleh masyarakat dan peserta KKN. Metode promosi dan pemasaran dengan membuatkan vidio desa wisata. Luaran dari program KKN-PPM ini berupa: Terciptanya fasilitas tempat rekreasi wisata air terjun berupa: terwujudnya fasilitas jalan menuju air terjun Jaga Satru. Terlaksananya pembuatan vidio desa wisata Duda Timur dan telah ditayangkan di Bali TV pada tanggal 10 September 2018, dan dapat di akses di https://youtu.be/DeMvPNHHD8U dan sudah ditonton oleh 1977. Air terjun sudah terpublikasikan dan dapat dilihat di http://lenteraesai.com/2018/08/21/kpk-hunting-foto-di-airterjun-jaga-satru, dan https://www.kabarnusa.com/2018/08/kesejukan-air-terjun-jagasatru.html. Peningkatan strata sosial masyarakat desa. Peningkatan perekonomian masyarakat desa. Terciptanya lingkungan yang bersih indah dan rapi.
\end{abstract}

Kata kunci: Penataan, air terjun, destinasi, wisata.

\section{ANALISA SITUASI}

Salah satu dari delapan Kecamatan yang terdapat di kabupaten Karangasem adalah Kecamatan Selat yang terdiri dari beberapa desa administrasi yaitu: Desa Duda Timur, Desa Duda, Desa Duda Barat, Desa Selat, Desa Pering, Desa Sebudi dll. Dengan luas wilayah 134,5 $\mathrm{km}^{2}$ yang dihuni oleh 69.083 jiwa yaitu laki-laki 34.669 jiwa dan perempuan 34.419 jiwa. Desa Duda Timur terdiri dari 9 Dusun antara lain: Dusun Pateh, Dusun Pesangkan, Dusun Pesangkan Anyar, Dusun Batu Gede, Dusun Dalem, Dusun Juwuk Legi, Dusun Wates Kangin, Dusun Wates Kaje, dan Dusun Putung.

\footnotetext{
${ }^{1}$ Mechanical Engineering Department of Udayana University, Badung-Bali Corresponding Outhurigksukadana@unud.ac.id

${ }^{2}$ Mechanical Engineering Department of Udayana University, Badung-Bali

${ }^{3}$ Mechanical Engineering Department of Udayana University, Badung-Bali
} 

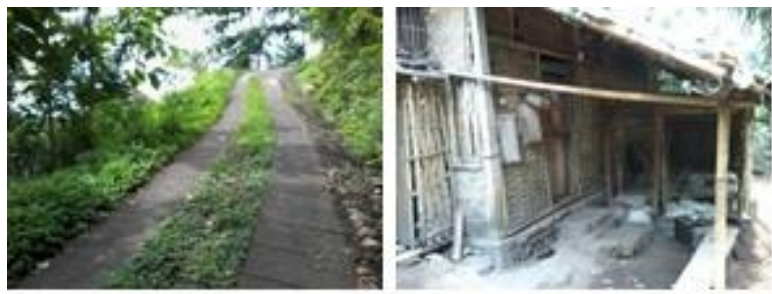

Gambar1. Jalan menuju dusun Pateh dan situasi rumah masyarakat (Sumber, Hasil Survey)

Dusun Pateh terletak pada daerah lereng perbukitan terdiri dari $180 \mathrm{KK}$ atau sekitar 900 jiwa, dengan penduduk tersebar di sekitar wilayah lereng Munduk Salak. Luas Wilayah Dusun Pateh sekitar $1,5 \mathrm{~km}^{2}$, yang seluruhnya merupakan daerah pertanian dan perkebunan. $85 \%$ jumlah penduduk Dusun Pateh bekerja sebagai petani, sisanya sebagai buruh, karyawan suwasta dan guru. Dusun Pateh merupakan dusun yang miskin dan tertinggal di wilayah Kabupaten Karangasem. Jadi juga merupakan daerah miskin dan tertinggal di Daerah Bali.

\section{POTENSI DESA}

Potensi dibidang Industri, wilayah desa Duda Timur yang memiliki dan memendam banyak potensi alam salah satunya yaitu potensi wisata air terjun Jaga Satru. Air terjun Jaga Satru memiliki ketinggian sekitar $30 \mathrm{~m}$, dengan kapasitas $20 \mathrm{~s} / \mathrm{d} 25$ liter/detik. Yang sangat cocok dimanfaatkan sebagai obyek wisata. Selain sebagai objek wisata juga memiliki potensi sebagai pembangkit energi untuk penerangan dan penggerak pompa. Selain itu juga Desa Duda Timur merupakan penghasil salak Bali yang sangat besar, tetapi akibat fluktuasi harga yang sangat tinggi mengakibatkan pada saat musim panen masyarakat mengalami kerugian akibat jatuhnya harga.
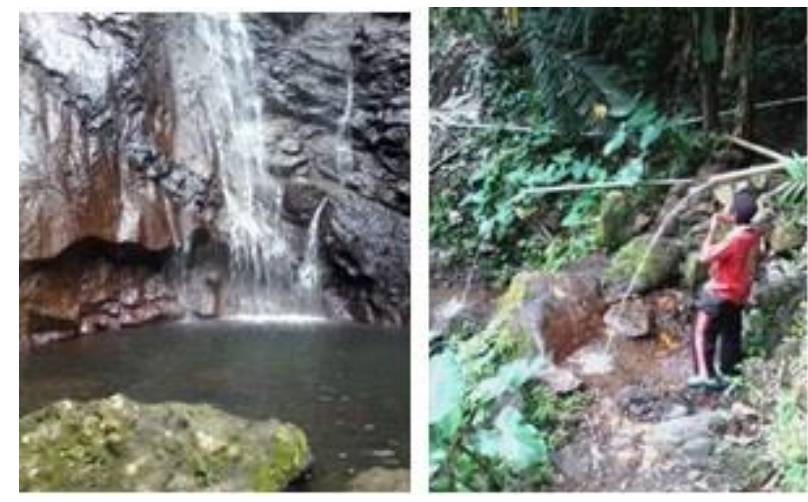

\section{Gambar2. Air Terjun Jaga Satru, sumber air Suda Mala \\ (Sumber, survey awal)}

Potensi dibidang sumber air, Desa Duda Timur memiliki sumber air bersih Suda Mala dimanfaatkan untuk pertanian dan kebutuhan sehari-hari. Sumber air Suda Mala memiliki kapasitas $10 \mathrm{~s} / \mathrm{d} 15$ liter/detik, kualitas air sangat bagus dan sangat cocok sebagai air minum. Tetapi karena lokasi pemukiman penduduk desa Duda Timur pada umumnya berada di lereng atau perbukitan menyebabkan pengelolaan sumber air Suda Mala untuk kebutuhan sehari-hari tidak optimal. Sehingga masyarakat mengalami kesulitan untuk mendapatkan air bersih.

Potensi dibidang Energi, Selain dapat sebagai obyek wisata Air terjun Jaga Satru yang memiliki ketinggian $50 \mathrm{~m}$, debit (kapasitas) 20 liter/detik memiliki potensi energi. Potensi energy dari air terjun Jaga Satru berkisar antara 4000 watt sampai 5000 watt. Jadi potensi energy sangat besar. Energy dapat dibangkitkan dengan penerapan teknologi kincir air (microhydro) atau teknologi pompa hydram. Teknologi ini digunakan pembangkit listrik untuk menerangai area obyek wisata, dan energy untuk mengangkat air ke pemukiman penduduk. 


\section{PERMASALAHAN MASYARAKAT.}

Permasalahan dibidang industri, Kurang tertatanya obyek wisata air terjun Jaga Satru dan sumber air Suda Mala. Belum adanya akses jalan yang layak menuju air terjun, belum tersedianya fasilitas wisata di areal air terjun, kurangnya pengetahuan masyarakat terhadap teknologi pasca panen tentang pengolahan dan produk olahan berbahan dasar Salak Bali, menyebabkan produk terbuang sia-sia saat panen tinggi dan produktivitas menjadi sangat rendah.

Permasalahan di bidang energi, karena sebagian besar wilayah Desa Duda Timur berada di wilayah perbukitan, menyebabkan akses energi berupa BBM/LPG sangat kurang. Masyarakat mengandalkan energi dari kayu bakar untuk memasak sehingga menyebabkan terganggunya hutan dan pohon, yang nantinya dapat mengancam terjadinya bencana erosi. Rendahnya pengetahuan masyarakat tentang teknologi gasifikasi.

\section{USULAN PENYELESAIAN MASALAH}

Usulan penyelesaian masalah dibidang industry, untuk meningkatkan perekonomian masyarakat desa dalam program KKN-PPM ini dilaksanakan beberapa kegiatan antara lain: Penataan akses jalan menuju obyek wisata air terjun, Penataan fasilitas di wilayah air terjun. Promosi wisata air terjun lewat blog, media internet lainnya, balihoo dll. Membentuk tim pengelola obyek wisata air terjun. Penyuluhan Tentang Keperasi/UMKM.

Usulan penyelesaian masalah dibidang energi, untuk menanggulangi ketersediaan energi pedesaan di dusun Pateh desa Duda Timur tanpa melakukan perusakan terhadap lingkungan adalah: Penerapan teknologi pompa hydram untuk menaikan air.

\section{METODE UNTUK MENGATASI PERMASALAHAN}

Untuk mengatasi permasalahan masyarakat dan dalam melaksanakan pemecahan terhadap permasalahan masyarakat digunakan beberapa metode antara lain: Metode Penyuluhan, penyuluhan dilakukan untuk memberikan pemahaman tentang kegiatan yang dilaksanakan dan meningkatkan pengetahuan masyarakat terhadap hal-hal dibicarakan. Metode Pendampingan, untuk menindak lanjukan pengetahuan yang diberikan ke masyarakat dengan terlibat secara langsung dengan masyarakat dalam setiap kegiatan. Metode Gotong Royong, melakukan kegiatan secara bersama-sama dengan masyarakat pemuda dan anak-anak. Metode Penerapan Teknologi Tepat Guna (TTG). Langsung bersama masyarakat membuat/membangun suatu teknologi yang mudah, murah dan berdaya guna.

Keberhasilan dari program KKN-PPM ini sangat dipengaruhi oleh rencana target capaian yang diinginkan oleh pelasana program dengan persetujuan. Adapun Target dari Program KKN-PPM di Dusun Pateh Desa Duda Timur Kecamatan Selat adalah: Berfungsinya air terjun Jaga Satru dan sumber air Suda Mala sebagai tempat rekreasi. Tertatanya akses jalan menuju obyek wisata air terjun Jaga Satru dan sumber air Suda Mala. Tertatanya lingkungan obyek wisata air terjun. Tersedianya fasilitas penunjang berupa tempat duduk, tempat istirahat, tempat mandi. Terealisasikannya blog desa wisata, terlaksana kegiatan promosi secara ofline dengan media reklame. Peningkatan Kesehatan Masyarakat dengan tersedianya sistem air bersih, tempat pemandian umum dan melalui penyuluhan PHBS. Peningkatan Produktivitas Masyarakat, dalam kerajinan melalui pengenalan koperasi/UMKM, Pengenalan teknologi pasca panen dan pengenalan Teknologi Tepat Guna. Efisiensi biaya dengan pemanfatan teknologi pompa hydram untuk sumber energi mengangkat air bersih kebutuhan sehar-hari. 
6. HASIL DAN LUARAN YANG DICAPAI

6.1. Pengerjaan Sistem Air Bersih Metode Pompa Mesin

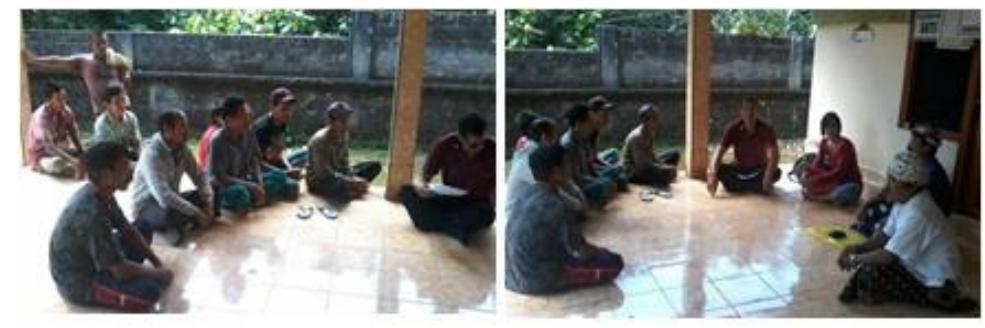

Gambar3. Kordinasi dengan pokja Air Bersih
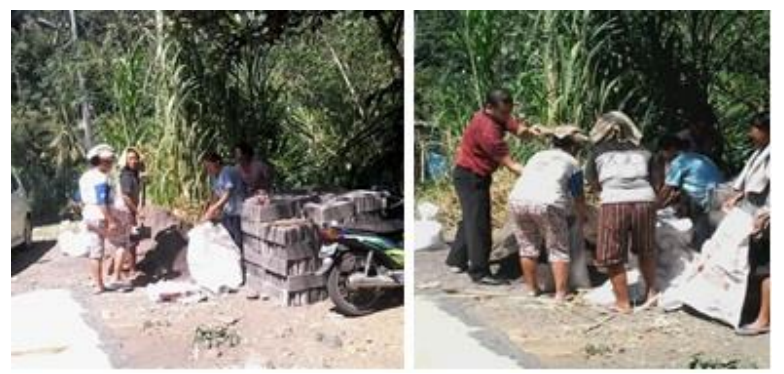

Gambar 4. Refaransir bahan broncaptering dan rumah pompa
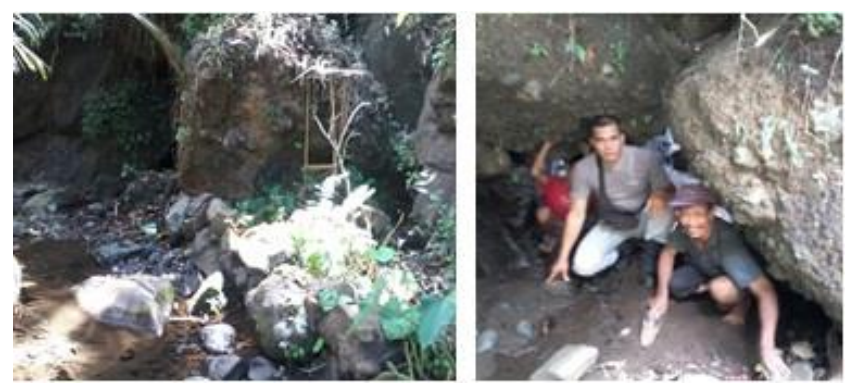

Gambar 5. Sumber air Tibu Mule

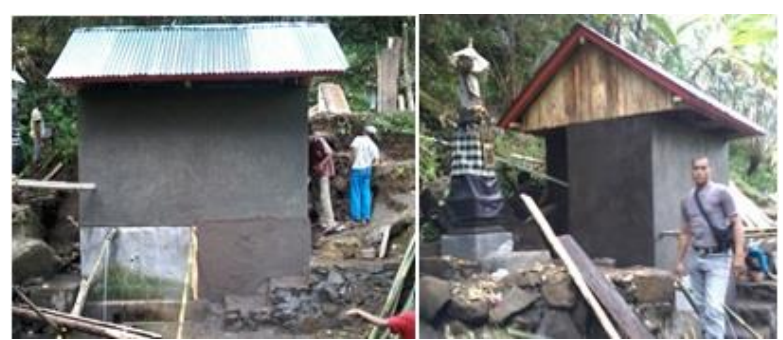

Gambar 6. Broncaptering dan Rumah Pompa



Gambar 7. Pemasangan Pompa Air dan uji coba 


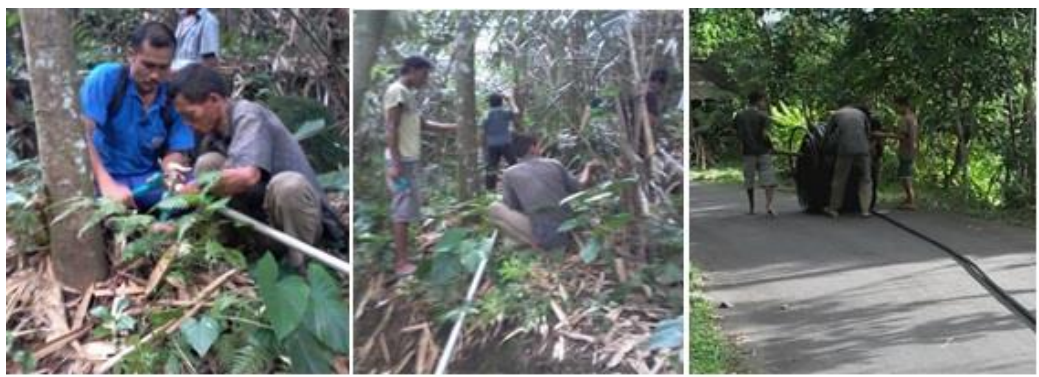

Gambar 8. Pemasangan Pipa Tekan pompa
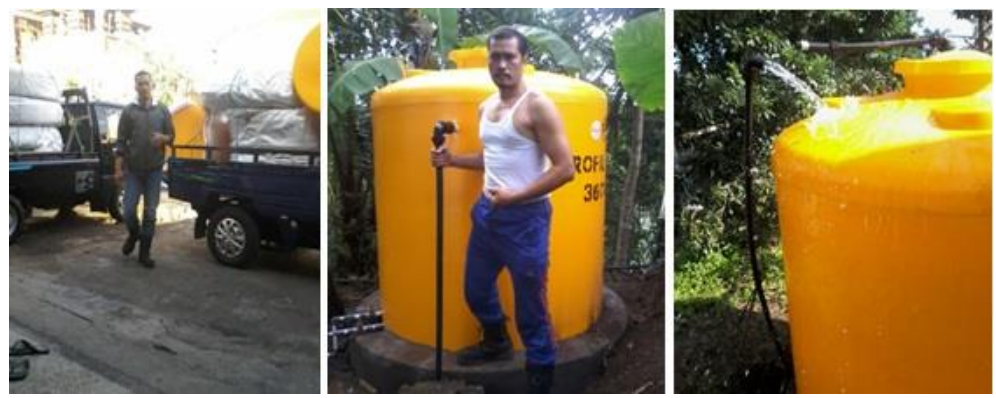

Gambar 9. Pemasangan Bak Penampungan Air

\subsection{Pengerjaan Sistem air metode gravitasi dan sistem sambungan rumah}
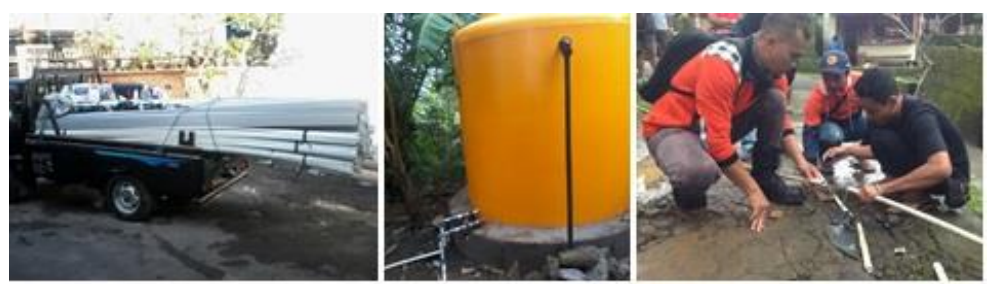

Gambar 10. Pemasangan sistem gravitasi

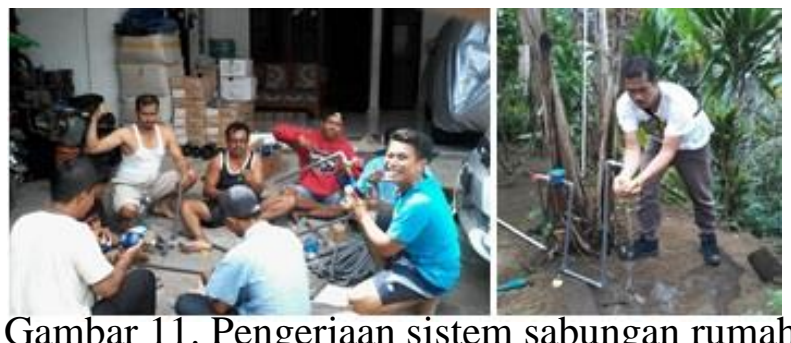

Gambar 11. Pengerjaan sistem sabungan rumah

\subsection{Perawatan Sistem Pompa Hydram}
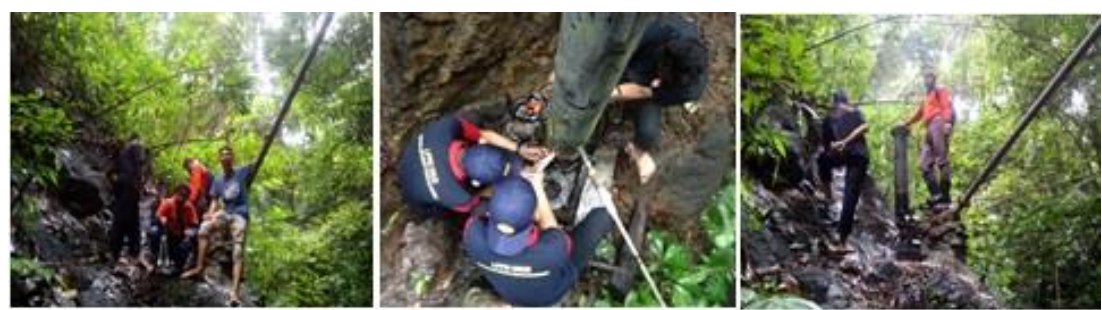

Gambar 12. Perbaikan sistem pompa hydram di Dusun Pateh

Perawatan Sistem Pompa Hidram, Melihat dan melakukan pengecekan kondisi pompa hidram untuk mengetahui letak kerusakan pada pompa. Kemudian mengambil kunci dan peralatan untuk melepas katup pompa dan membersihakan pompa dari sampah daun. Katup 
pompa yang dilepas kemudian dibawa ke Tabanan untuk diperbaiki. Selama kurang lebih satu minggu diperbaiki katup pompa dibawa kembali ke air terjun Jagasatru untuk dipasang. Satu minggu kemudian kondisi pompa dicek kembali, ternyata ada kebocoran yang menyebabkan air tidak sampai ke tempat penampungan. Sehingga karet katup buang kurang besar dan harus diganti sehingga tidak terjadi kebocoran lagi. Setelah itu dilakukan pemasangan pipa distribusi air yang bocor dari depan Balai Banjar Pateh sampai ke tempat penampungan air. Untuk menghindari karat maka dilakukan pengecatan pada bagian pompa yang berkarat dan pada sambungan pipa. Untuk menangani masalah rusaknya pondasi dari pompa hidram, rencananya pondasi dicor agar kuat menerima tekanan dari pompa. Program tersebut dilakukan seiring pelaksanaan kegiatan KKN-PPM XVII Universitas Udayana dan dimanfaatkan secara berkelanjutan. Hal ini dilakukan oleh masyarakat sekitar untuk turun langsung bersama peserta KKN dalam mendukung program air bersih yang dilakukan di areal air terjun Jagasatru. Penerapan teknologi Hidram ini menjadi harapan besar warga untuk mendapatkan air bersih sebagai keperluan rumah tangga di tempat tinggalnya. Perawatan teknologi hidram meningkatkan sistem kerja pompa hidram sehingga mampu memberikan pemerataan air bersih dari sumber mata air yang terdapat di air terjun jagasatru serta dapat didistribusikan ke rumahrumah warga yang terdapat di Dusun Pateh.

Pembuatan tempat bak penampung air volume bak $5000 \mathrm{~L}$ di Dusun Wates Kaja, Kurangnya penyuplay sistem air bersih di Dusun Wates Kaja, Desa Duda Timur menjadi landasan program air bersih ini dilakukan di daerah tersebut. Untuk membantu masyarakat dalam pemenuhan kebutuhan air bersih di Dusun Wates Kaja sebagai salah satu upaya yang dilakukan agar mendapatkan aliran air bersih yang lebih banyak untuk digunakan sebagai keperluan masyarakat sekitar. Program tersebut dilakukan seiring pelaksanaan kegiatan KKNPPM XVII Universitas Udayana dan dimanfaatkan secara berkelanjutan. Hal ini dilakukan oleh masyarakat sekitar untuk turun langsung bersama peserta KKN dalam mendukung program air bersih yang dilakukan di Dusun Wates Kaja. Pembuatan bak air ini dapat menampung banyak air yang di ambil dri sumber air dengan menggunakan teknologi mesin Diesel sehingga mampu memberikan pemerataan air bersih dari sumber mata air serta dapat didistribusikan ke rumahrumah warga yang terdapat di Dusun Wates Kaja. Pembangunan Bak Air 5000 L di harapkan dapat membantu warga dalam penyuplay air bersih dan pengunaannya dapat memberikan dampak yang positif bagi warga Dusun Wates Kaja.

\subsection{Penataan Air Terjun Jaga Satru}

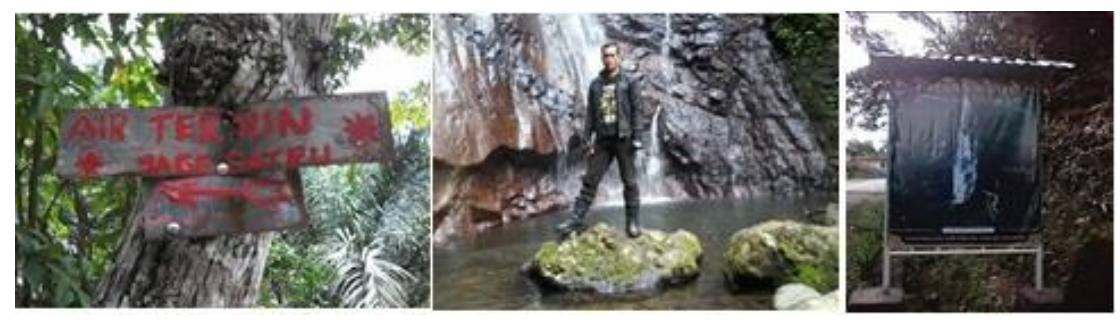

Gambar 13. Pembuatan Plang Nama Air Terjun

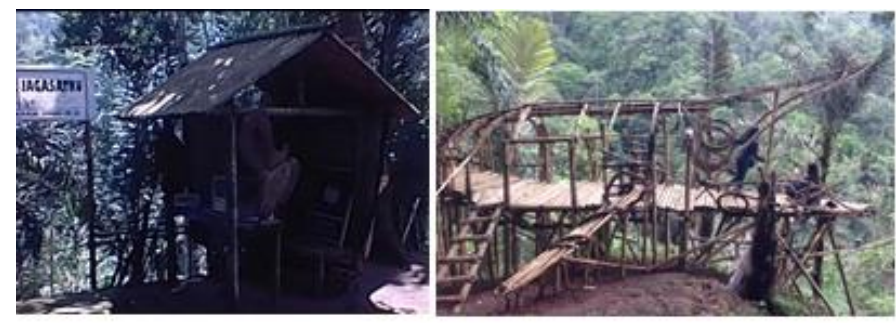

Gambar 14. Penataan Destinasi Wisata Air Terjun Jaga Satru 



Gambar 15. Persiapan pengerjaan tangga menuju air terjun Jaga Satru

Promosi Desa Duda Timur Sebagai Destinasi Pariwisata, Setelah melakukan koordinasi dengan pihak kepala desa Duda Timur dan para kepala dusun Duda Timur tentang pemetaan potensi wisata desa, maka selanjutnya dibuat naskah narasi dan konsep video pariwisata. Shoot video dilaksanakan di Bukit Putung, Bukit Batur Sari, Air Terjun Jagasatru, Pasraman Mulat Sarira dan Beji Dedari Suci. Setelah rampung take video dilakukan proses editing dan selanjutnya video diupload di media sosial. Dilaksanakan pula acara photo hunting di Air Terjun Jagasatru dengan menggunakan model Teruni Bali 2018, Bagus Karangasem 2014, Jegeg Karangasem 2015, selebgram dan beberapa anak kkn Duda Timur. Acara tersebut diikuti dengan lebih kurang 20 orang photographer dengan sistem donasi. Hasil foto diupload di masing-masing instagram photographer dengan menggunakan hastag wajib \#airterjunjagasatru. Kegiatan ini juga di post di media cetak seperti Bali Post, Warta Bali, media online lenteraesai.com.

Kurangnya pemasaran dan pempublikasian yang baik untuk mendapatkan daya tarik wisatawan. Media sosial di zaman seperti sekarang sangat penting untuk memasarkan potensi pariwisata, karena implikasinya yang sangat besar. Dengan dibuatnya film documenter tentang desa Duda Timur dan Acara Photo Hunting di Desa Duda Timur yang diupload di media sosial instagram dan website desa maka diharapkan mampu meningkatkan kunjungan wisatawan ke Duda Timur.

Wisatawan lebih mudah mengetahui tentang potensi pariwisata yang ada di Desa Duda Timur sehingga dapat dikatakan hal tersebut sebagai refrensi bagi wisatawan dengan penerapan pemasaran secara e-tourism. Diharapkan agar lebih banyak lagi yang datang dan berkunjung ke lokasi wisata yang ada di Desa Duda Timur.

Penataan Air Terjun Jagasatru Di Dusun Pateh, Desa Duda Timur, Kecamatan Selat, Kabupaten Karangasem sebagai objyek wisata. Kegiatan penataan Air Terjun Jagasatru Di Dusun Pateh, Desa Duda Timur difokuskan pada penataan prasarana fisik, yaitu pembuatan jalan dan tangga Air Terjun Jagasatru. Tujuan penataan Air Terjun Jagasatru, agar sarana prasarana air terjun menjadi lebih lengkap dan lebih menarik perhatian turis lokal maupun mancanegara, sehingga mereka tidak melakukan kunjungan sekali dua kali saja, namun berkali-kali karna potensi wisata air terjun terpenuhi dengan akses yang sudah jauh lebih baik.

Hasil dari kegiatan adalah: Jalan menuju Air Terjun Jagasatru menjadi lebih baik dan lebih kokoh. Mempermudah akses wisatawan yang ingin mengunjungi Air Terjun Jagasatru. Meningkatkan daya tarik wisata Air Terjun Jagasatru. Dari kegiatan ini diharapkan dapat memenuhi komponen produk pariwisata Air Terjun Jagasatru, sehingga membuat daya tarik wisata Air Terjun Jagasatru makin meningkat dan masyarakat sekitarnya dapat menikmati dan memanfaatkan keberadaan Air Terjun Jagasatru dalam segi pariwisata. Serta dapat pula meningkatkan perekonomian masyarakat sekitar Air Terjun Jagasatru, Dusun Pateh, Desa Duda Timur.

\section{SIMPULAN}

Berdasarkan pemaparan program KKN PPM XVII Desa Duda Timur, Kecamatan Selat, Kabupaten Karangasem yang telah direncanakan dapat berjalan dengan lancar. Program-program yang telah dilaksanakan terdiri dari bidang monodisipliner dan multidisipliner yaitu: bidang peningkatan produksi, bidang prasarana fisik, bidang sosial 
budaya, dan bidang kesehatan masyarakat. Program yang dilaksanakan telah sesuai dengan konsep KKN PPM yang ditetapkan oleh LPPM Universitas Udayana dan sudah sesuai dengan tema yang dicanangkan oleh kelompok KKN PPM XVII Desa Duda Timur yaitu mengarah pada pemberdayaan masyarakat dengan cara peningkatan kualitas sumber daya manusia (SDM) melalui beberapa penyuluhan dan sosialisasi serta kegiatan-kegiatan yang dapat mendidik masyarakat khususnya para pelajar. Semua kegiatan yang telah dilakukan telah dikoordinasikan dan mendapatkan kerjasama baik dari berbagai pihak seperti Kepala Desa, Kepala Dusun, Sekolah, KWT, dll. Banyak halangan yang dihadapi dalam pelaksanaan semua program di Desa Duda Timur tetapi dapat diatasi dan mendapatkan respon yang positif dari pihak masyarakat.

\section{Acknowledgements}

The author thanks to the Ministry of Research Technology and Higher Education of the Republic of Indonesia and LPPM University of Udayana for supporting this research and paper through The Grants at 2017 - 2018.

\section{DAFTAR PUSTAKA}

Anonim, 2013, "Panduan Pelaksanaan Hibah Kuliah Kerja Nyata Pembelajaran Pemberdayaan Masyarakat (KKN-PPM)" DP2M Direktorat Jenderal Pendidikan tinggi Kementerian Pendidikan dan Kebudayaan

Anonim, 2015, Buku Pedoman Akademik Fakultas Teknik Universitas Udayana, Fakultas Teknik UNUD.

Anonim, 2010, Statistik Desa Duda Timur,

Anonim, 2016, "Panduan Pelaksanaan Penelitian dan Pengabdian Kepada Masyarakat

di Perguruan Tinggi Edisi X" Direktorat Riset dan Pengabdian kepada Masyarakat,Direktorat Jenderal Penguatan Riset dan Pengembangan Kementerian Riset, Teknologi, dan Pendidikan Tinggi 